\title{
The Prediction of Crack Growth in Bonded Joints under Cyclic-Fatigue Loading. Part I: Experimental Studies
}

\author{
H. HADAVINIA, A.J. KINLOCH*', M.S.G. LITTLE and A.C. TAYLOR
}

Department of Mechanical Engineering, Imperial College London, Exhibition Road, London, SW7 $2 A Z, U K$.

\begin{abstract}
$\underline{\text { Abstract }}$
The performance of adhesively-bonded joints under monotonic and cyclic-fatigue loading has been investigated using a fracture-mechanics approach. The joints consisted of an epoxy film adhesive which was employed to bond aluminium-alloy substrates. The effects of undertaking cyclic-fatigue tests in (a) a 'dry' environment of $55 \%$ relative humidity at $23^{\circ} \mathrm{C}$, and (b) a 'wet' environment of immersion in distilled water at $28^{\circ} \mathrm{C}$ were investigated. In particular, the influence of employing different surface pretreatments for the aluminium-alloy substrates was examined. In addition, singlelap joints were tested under cyclic fatigue loading in the two test environments, and a back-face strain technique has been used which revealed that crack propagation, rather than crack initiation, occupied the dominant proportion of the fatigue lifetime of the single-lap joints. In Part II, the data obtained in the present Part I paper will be employed to predict theoretically the lifetime of the adhesively-bonded single-lap joint specimens.
\end{abstract}

Keywords: C. Fracture mechanics; D. Fatigue; Durability, E. Joint design; Life prediction.

\footnotetext{
* Corresponding author

E-mail: a.kinloch@imperial.ac.uk, Fax:+44 (0)20 75947017
} 


\section{Nomenclature}

a Crack length

$a_{o} \quad$ Griffith (inherent) flaw size

$b \quad$ Width

CAE Chromic-acid etch

D Linear ('Region II') coefficient

$E_{a} \quad$ Young's modulus of adhesive

FE Finite element

G Strain-energy release-rate

$G_{c} \quad$ Adhesive fracture energy

$G_{\max } \quad$ Maximum strain-energy release-rate applied in a fatigue cycle

$G_{t h} \quad$ Threshold strain-energy release-rate

GBD Grit-blast and degrease

LEFM Linear-elastic fracture -mechanics

LoF Locus of failure

$m \quad$ geometry constant

$N \quad$ Number of cycles

$N_{f} \quad$ Number of cycles to failure

$n \quad$ Linear ('Region II') curve-fitting constant

$n_{1} \quad$ Threshold ('Region I') curve-fitting constant

$n_{2} \quad$ Fast fracture ('Region III') curve-fitting constant

$P \quad$ load

PAA Phosphoric-acid anodise

$T \quad$ Load per unit width applied to the single-lap joint

$T_{f} \quad$ Failure load per unit width for monotonic loading

$T_{\max } \quad$ Maximum load per unit width applied in a fatigue cycle

$T_{t h} \quad$ Threshold value of the maximum load per unit width for the single-lap joint

TDCB Tapered double-cantilever beam

$t_{a} \quad$ Adhesive layer thickness

$u_{\max } \quad$ Maximum displacement

$u_{\min } \quad$ Minimum displacement

XPS X-ray photoelectron spectroscopy

$\sigma_{f} \quad$ Tensile strength of the single-lap joint 


\section{Introduction}

The advantages of employing adhesive bonding to join materials in structural applications are well known. They include (a) an ability to join dissimilar materials and (b) the imparting of an improved stress distribution to the joint, when compared to using mechanical fasteners. However, one of the main concerns in many industries, which limits the wider application of adhesives, is the long-term service-life of adhesive joints especially when exposed to hot/wet environments under cyclic fatigue loading $[1,2]$. These concerns are exacerbated by the problems in accurately predicting the service life of adhesive joints under such conditions. Indeed, the ability to describe quantitatively the performance of bonded joints and to predict their lifetime would be powerful tools, enabling designers to make wider and more efficient use of adhesive bonding.

In previous work [3,4] a method for predicting the lifetime of adhesively-bonded joints and components has been proposed. This prediction method consists of three steps. Firstly, fracturemechanics data must be obtained under cyclic loading in the environment of interest and modelled, resulting in an expression which relates the rate of crack growth per cycle, $d a / d N$, to the maximum applied strain-energy release-rate, $G_{\max }$, in a fatigue cycle. Secondly, this relationship is then combined with an analytical or a computational description of the variation of $G_{\max }$ with the crack length and applied load in the joint, or component. Obviously, these theoretical calculations consider the detailed design aspects of the bonded joint, or bonded component. Thirdly, integration of this combined expression then gives a prediction for the cyclic-fatigue lifetime of the bonded joint or component. A basic theme behind this methodology is that the fracture-mechanics parameters are considered to be characteristic of the adhesive system and the test environment, and such material/test-environment 'property' data can be obtained in a relatively short time-scale. Thus, the fracture-mechanics data may be used to predict the performance of other designs of bonded joints, components and structures over a relatively long time-scale.

In Part I of the present work, fracture-mechanics data are obtained using the tapered doublecantilever beam (TDCB) test geometry. The effects of employing different surface pretreatments and test environments are considered. These data are described using the modified Paris Law model. Also, the fatigue lifetime of single-lap joints is investigated. In Part II, the fracture-mechanics data obtained using the TDCB specimens will be employed to predict the lifetime of the adhesively-bonded singlelap joint specimens [5]. 


\section{Experimental}

\subsection{Materials}

The substrates used throughout the present work were prepared from an aluminium alloy (UK code: 2L93; International Code: EN AW 2014A) and were bonded using a hot-curing toughened-epoxy adhesive, "EA9628 UNS” (i.e. unsupported with no carrier), manufactured by Hysol Dexter (USA). This was supplied as a film with a nominal thickness of $0.24 \mathrm{~mm}$. Both the TDCB and single-lap joint specimens were cured in two stages. Firstly, they were cured for 90 minutes at $95^{\circ} \mathrm{C}$, and secondly the temperature was increased to $120^{\circ} \mathrm{C}$ and held for 30 minutes. The TDCB specimens were then allowed to cool overnight. On the other hand, the single-lap joint specimens were then cooled to $65^{\circ} \mathrm{C}$, when the pressure was released, and they were allowed to air cool to room temperature. An important aspect, as discussed later, is that in the case of the TDCB joints only a relatively low pressure was applied to the joints during the bonding procedure, just sufficient to keep the joint together. On the other hand, in the case of the single-lap joints a pressure of $500 \mathrm{kPa}$ was applied during the bonding procedure.

\subsection{Surface Pretreatment Procedures}

Prior to bonding, the substrates were pretreated using either a gritblast and degrease (GBD) treatment, a chromic acid etch (CAE), or a phosphoric acid anodise (PAA) process [6]. For the GBD-pretreated joints, the substrates were first washed with water to remove any gross contamination, after which they were degreased with acetone. The substrates were lightly grit-blasted with clean, alumina grit and any grit removed with compressed air. They were then cleaned with acetone, washed in cold tap water and dried at $60^{\circ} \mathrm{C}$, for 20 minutes, prior to being bonded.

For CAE-pretreated joints, the GBD procedure was followed, except that the substrate was transferred to the $\mathrm{CAE}$ bath preheated to $68^{\circ} \mathrm{C}$ without being first dried, and the substrates were etched in the CAE bath for 20 minutes. On removal from the etch bath, they were rinsed for 5 minutes in cold tap water and then for 10 minutes in distilled water. They were dried at $40^{\circ} \mathrm{C}$ for 20 minutes, prior to being bonded. For the PAA-pretreated joints, the substrates were pretreated as for the CAE pre-treatment. Then they were transferred to a phosphoric acid bath preheated to $25^{\circ} \mathrm{C}$. A potential of $10 \pm 0.5 \mathrm{~V}$ was applied for 20-25 minutes. The substrates were then rinsed for 5 minutes in cold tap water, then placed in a tank of tap water for 5 to 15 minutes and then dried at $60^{\circ} \mathrm{C}$ for 20 minutes, prior to being bonded. (These procedures follow the relevant standards [1].)

The specimens were tested under monotonic loading or cyclic-fatigue loading conditions, as described below. 


\subsection{Fracture-Mechanics Tests}

Adhesively-bonded tapered double-cantilever beam (TDCB) specimens were used for the fracturemechanics tests. The full details of the specimen geometry and the test procedure are available elsewhere [6-8], although a brief summary is given here and the test specimen is shown schematically in Figure 1a. The adhesive fracture energy, $G_{c}$, under monotonic loading was measured using a constant rate of displacement of $1.0 \mathrm{~mm} / \mathrm{min}$. These tests were conducted in 'dry' conditions, i.e. at $23 \pm 1^{\circ} \mathrm{C}$ and at approximately $55 \%$ relative humidity.

The same specimen geometry was also used in the fatigue studies to obtain the relationship between the rate of crack growth, $d a / d N$, and the maximum strain-energy release-rate, $G_{\max }$, applied during a fatigue cycle. These tests were performed using a sinusoidal loading waveform with a frequency of $5 \mathrm{~Hz}$, and a displacement ratio, $u_{\min } / u_{\max }$, of 0.5 , which were convenient test parameters. A range of maximum displacements, $u_{\max }$, was used to obtain data over a wide range of values of $G_{\max }$. The tests were conducted (a) in 'dry' conditions of $23 \pm 1^{\circ} \mathrm{C}$ and approximately $55 \%$ relative humidity, and (b) in 'wet' conditions of immersion in distilled water at $28 \pm 1^{\circ} \mathrm{C}$ [6]. The crack length was measured at intervals using a vernier microscope. In addition, crack propagation gauges were used to measure the crack length for the tests in the 'dry' environment [6,9]. This latter technique confirmed the accuracy of the simpler method using the vernier microscope. These cyclicfatigue tests typically lasted from a few hours to a few weeks.

\subsection{Single-Lap Joints}

The single-lap joint specimens were prepared in accordance with ASTM D1002, and manufactured as panels. This involved plates of $2.5 \mathrm{~mm}$ thick aluminium alloy being pretreated and then adhesivelybonded with an overlap of $12.7 \mathrm{~mm}$. The plates were subjected to a pressure of $500 \mathrm{kPa}$ in a press and cured, during which procedure naturally-occurring spew fillets of adhesive formed at the ends of the overlap. The plates were then cut to the width required by the ASTM standard. i.e. $25.4 \mathrm{~mm}$, see Figure 1b.

The joints were tested under monotonic loading using a constant displacement rate of 1 $\mathrm{mm} / \mathrm{min}$ in a 'dry' environment. Cyclic-fatigue tests were performed using a sinusoidal loading waveform with a frequency of $5 \mathrm{~Hz}$, and a displacement ratio, $u_{\min } / u_{\max }$, of 0.5 , as for the fracturemechanics tests. The cyclic-fatigue tests were performed in both the 'dry' and the 'wet' environments. 


\section{Fracture-Mechanics Tests Using TDCB Specimens}

\subsection{Monotonically-loaded Tests}

Monotonically-loaded tests were carried out in a 'dry' environment using the TDCB specimens where the joints had been pretreated using the GBD, CAE or PAA surface pretreatments. The measured values for the adhesive fracture energy, $G_{c}$, are presented in Table 1 . A mean $G_{c}$ value of $1600 \pm 150$ $\mathrm{J} / \mathrm{m}^{2}$ was measured for the CAE- and PAA-pretreated joints, and all these joints failed via cohesive failure through the adhesive. However, for the GBD-pretreated specimens a $G_{c}$ value of only $600 \pm 100$ $\mathrm{J} / \mathrm{m}^{2}$ was measured, and the locus of failure was found to be a mixture of interfacial and cohesive fracture, which explains the lower value of $G_{c}$ for these joints.

\subsection{Cyclic Fatigue Studies}

\subsubsection{Modelling The Fracture-Mechanics Data}

The lifetime-prediction procedure uses the modified form of the Paris Law $[10,11]$ to describe the sigmoidal-shaped relationship between the rate of crack growth per cycle, $d a / d N$, and the maximum applied strain-energy release-rate, $G_{\max }$, per cycle:

$$
\frac{d a}{d N}=D G_{\max }^{n}\left\{\frac{1-\left(\frac{G_{t h}}{G_{\text {max }}}\right)^{n_{1}}}{1-\left(\frac{G_{\text {max }}}{G_{C}}\right)^{n_{2}}}\right\}
$$

where the values of the fatigue coefficients $D, n, n_{1}$ and $n_{2}$ are calculated from the experimental data. The values of $D$ and $n$ refer to the linear 'Region II', $n_{1}$ to the threshold 'Region I' and $n_{2}$ to the fast fracture 'Region III'. The meaning and fitting of these coefficients has been discussed in detail previously $[3,4,6,9]$ and only a brief summary is given here. Initially, experimental data from the linear 'Region II', see Figures 2 and 3 for example, are fitted with a linear slope of gradient $n$, and intercept $D$. The values of $n_{1}$ and $n_{2}$ represent the acuity of the change in gradient, as may be seen from Figures 2 and 3, due to the transition in the fatigue data from the linear 'Region II' to the threshold 'Region I'; and also due to the transition in the data from the linear 'Region II' to the near fast-fracture 'Region III'. The values for $n_{1}$ and $n_{2}$ were constrained in their range of possible values, as suggested by Taylor [9], and in the present work were found to be such that $n_{1}=n_{2}=10$. (If the values of $n_{1}$ and $n_{2}$ are not constrained in the range that they can take, then the slope of the 'Region II' relationship deviates from that already calculated. Further, in the present work, the value of $n_{2}$ has been chosen to be equal to $n_{1}$, since it was not possible to obtain data from the near fast-fracture region, as the rate of crack growth was too large to be measured accurately due to the steep nature of 
the $\log d a / d N$ versus the $\log G_{\max }$ plot in this region.) The suitability of these values was confirmed using an 'EXCEL macro' which changes the coefficients of the modified Paris Law fit to minimise the sum of the squares of the residual error between the experimental data and the theoretical fit [4]. The values of $D, n, n_{1}$ and $n_{2}$ so deduced are shown in Table 2 and the agreement between the theoretical relationships, as given by Equation (1), and the experimental data is illustrated below in subsequent figures.

The initial flaw size is assumed to be equal to the 'Griffith' flaw size, $a_{o}$, and was calculated using [4]:

$$
a_{0}=\frac{E_{a} G_{c}}{\pi \sigma_{f}^{2}}
$$

where $\sigma_{f}$ is the tensile strength of the single lap joint as measured from monotonic loading. The values of $a_{0}$ so deduced are given in Table 2. (Whether the values of $a_{0}$ so deduced really reflect pre-existing defects or cracks in the adhesive (or at the interface) or form during the early stages of loading is a matter of some debate. However, the results from the calculations undertaken in Part II are not significantly dependent upon the exact values employed for $\left.a_{0}[4,6,9]\right)$. A value of $2.8 \mathrm{GPa}$ was used for the Young's modulus, $E_{a}$, of the adhesive.

\subsubsection{GBD-pretreated Joints}

The fatigue data for the GDB-pretreated joints tested in the 'dry' and 'wet' environments are shown in Figure 2. An adhesive fracture energy, $G_{c}$, of $600 \mathrm{~J} / \mathrm{m}^{2}$ was measured from the monotonically-loaded tests, whilst fatigue threshold fracture energy, $G_{t h}$, values of $125 \mathrm{~J} / \mathrm{m}^{2}$ and $25 \mathrm{~J} / \mathrm{m}^{2}$ were measured in the 'dry' and 'wet' environments, respectively. The fatigue coefficient values derived from these data by fitting Equation (1) to the results are given in Table 2, and it may be seen from Figure 2 that the agreement between the theoretical relationship, Equation (1), and the experimental data is excellent. It should be noted that different values of the coefficients were calculated for the experimental data from the specimens tested in the 'dry' and 'wet' environments.

\subsubsection{CAE-pretreated Joints}

The experimental results for the fatigue tests from the TDCB specimens in the 'dry' and the 'wet' environments employing the CAE pretreatment are shown in Figure 3. An adhesive fracture energy, $G_{c}$, of $1550 \pm 50 \mathrm{~J} / \mathrm{m}^{2}$ and a fatigue threshold fracture energy, $G_{t h}$, of $200 \mathrm{~J} / \mathrm{m}^{2}$ was measured for both the 'dry' and 'wet' environments. The fatigue coefficient values derived from these data by fitting Equation (1) to the results are given in Table 2, and again it may be seen from Figure 3 that the 
agreement between the theoretical relationship, Equation (1), and the experimental data is excellent. Also, it may be noted that when the CAE surface pretreatment is employed, the different environmental conditions have no significant effects on the cyclic fatigue relationship, as ascertained from using the TDCB joints.

\subsubsection{PAA-pretreated Joints}

Here, an adhesive fracture energy, $G_{c}$, of $1650 \pm 100 \mathrm{~J} / \mathrm{m}^{2}$ was measured, whilst values of the fatigue threshold fracture energy, $G_{t h}$, of $200 \mathrm{~J} / \mathrm{m}^{2}$ and $50 \mathrm{~J} / \mathrm{m}^{2}$ were measured in the 'dry' and 'wet' environments, respectively, as may be seen in Figure 4. The fatigue coefficient values derived from these data by fitting Equation (1) to the results are given in Table 2 and again the agreement between the theoretical relationship, Equation (1), and the experimental data is excellent. With the PAApretreated tests, clearly the test environment has a dramatic effect on the fatigue behaviour of the joints. This is reflected in the change in the locus of failure from being cohesive through the adhesive layer in the 'dry' environment but apparently along the adhesive/oxide interface for the tests conducted in the 'wet' environment, and hence the accompanying decrease in the value of $G_{t h}$ for the latter environment.

\section{Experimental Studies of Single-Lap Joints}

\subsection{Monotonically-loaded Tests}

Monotonically-loaded tests were undertaken in a 'dry' environment employing single-lap joint specimens, using the GBD, CAE or PAA surface pretreatment. The results of the monotonicallyloaded strengths of the various types of lap joint are summarised in Table 3. For the CAE- and PAApretreated specimens the locus of joint failure was visually assessed to be via cohesive failure through the adhesive, whilst for the GBD-pretreated specimens the locus of failure was a mixture of interfacial/cohesive fracture. These observations on the loci of failure for the single-lap joint specimens tested under monotonic-loading conditions are identical to those recorded for the corresponding TDCB specimens tested under monotonic-loading conditions.

\subsection{Fatigue Studies}

\subsubsection{Introduction}

Cyclic-fatigue tests were conducted using single-lap joint specimens, again prepared employing the GBD, CAE or PAA pretreatments. The maximum loads that could be employed for the fatigue tests were determined from the monotonically-loaded strengths given in Table 3. The data below are presented in the form of conventional fatigue load versus number of cycles to failure curves, i.e. in the present case the maximum applied load per unit width, $T_{\max }$, in a fatigue cycle versus the number of cycles to failure, $N_{f}$. The fatigue threshold values of the maximum applied load per unit width, $T_{t h}$, are 
quoted at a value of $N_{f}=10^{7}$ cycles, except for the CAE- and PAA-pretreated lap joints tested in the 'wet' environment when a value of $N_{f}=10^{6}$ cycles was taken to avoid extrapolating.

\subsection{2 'Dry’ Environmental Tests}

The results of the 'dry' fatigue behaviour of the single-lap joint specimens, prepared using the GBD, CAE and PAA pretreatments, are shown in Figure 5. Values measured for the threshold value, $T_{\text {th }}$, are given in Table 3. The threshold values for the GBD, CAE and PAA specimens were determined to be 85, 215 and $225 \mathrm{kN} / \mathrm{m}$, respectively. The locus of failure for the specimens with the GBD pretreatment was found to be a mixture of partially cohesive through the adhesive layer and partially interfacial, as was recorded for the monotonically-loaded tests. For the CAE- and PAA-pretreated specimens, the locus of failure was found to remain cohesive through the adhesive layer. Hence, a direct correlation exists for the single-lap joint specimens between possessing a relatively high threshold, $T_{t h}$, value and the locus of failure being cohesive through the adhesive.

\subsection{3 'Wet’ Environmental Tests}

The 'wet' fatigue behaviour of the single-lap joint specimens, prepared using the GBD, CAE and PAA pretreatments, was also assessed and the results are shown in Figure 6. The fatigue performance of the GBD pretreatment was found to decrease significantly on exposure to the 'wet' environment, with a relatively low fatigue threshold value of $50 \mathrm{kN} / \mathrm{m}$ being measured. It was found, that the 'wet' fatigue performance could be correlated with the increased degree of interfacial failure, as ascertained by visual assessment of the failed joints. This observation corresponds to those made in connection with the fatigue behaviour of the TDCB joints in the 'wet' environment, see Table 1.

The fatigue performances of the CAE- and PAA-pretreated single-lap joint specimens were relatively unaffected upon exposure to the 'wet' environment, with threshold values of 215 and 225 $\mathrm{kN} / \mathrm{m}$ being measured. The locus of failure was found be mostly cohesive through the adhesive layer, as was observed for cyclic fatigue tests conducted in the 'dry' environment, with only small regions of apparent interfacial failure being observed. However, a few instances of substrate failure were observed in the PAA-pretreated joints tested in the 'dry' environment, see Figure 6. Thus, whilst the observations from the fatigue behaviour of the single-lap joint tests in the 'wet' environment are similar to the corresponding TDCB tests in the case of the CAE-pretreated joints, there are clear discrepancies in the case of the PAA-pretreated joints, c.f. Tables 1 and 3.

\section{Mechanisms of Failure}

The detailed mechanisms of failure have been reported [2] previously, and only the details necessary for the present paper are given here. 


\subsection{GBD-pretreated Joints}

From examining the results in Tables 1 and 3, it is clearly evident that the results from both the TDCB and single-lap joints indicate that, even in the 'dry' environment, the intrinsic adhesion at the adhesive/oxide interface for the GBD-pretreated joints is inadequate to prevent some degree of interfacial failure occurring. This is in direct contrast to the 'dry' results for the CAE- and PAApretreated joints where only cohesive failure through the adhesive layer was observed. Previous work has ascribed the poor adhesion in the case of the GBD-pretreated joints to the high level of carbon contamination that is present and the relatively high degree of roughness of the grit-blasted surface. Both of these factors lead to poor wetting by the epoxy-film adhesive and relatively low interfacial adhesion. The effect of conducting the GBD-pretreated TDCB and single-lap joint tests in the 'wet' environment is to give a purely interfacial failure at the adhesive/oxide interface, as was ascertained using X-ray photoelectron spectroscopy (XPS), with an accompanying decrease in the fatigue performance of the joint. This was considered to arise from the thermodynamic instability of the adhesive/grit-blasted oxide interface in water.

\subsection{CAE-pretreated Joints}

In both the TDCB and the single-lap joint tests, and in both the 'dry' and 'wet' test environments, the locus of failure in the CAE-pretreated joints was cohesive through the adhesive layer. This is directly reflected in the very good mechanical performance of these joints in both test environments. In these joints it appears that the open, whisker-like, microstructure of the CAE-generated oxide allowed the adhesive to penetrate to give a well-wetted interface with the formation of a 'micro-composite' interphase. Such a 'micro-composite' interphase offers many benefits which may ensure the integrity of the interphase region, and so leads to a cohesive fracture of the joint through the adhesive layer. For example, after the adhesive has been cured during the preparation of the bonded joint, the porous nature of the oxide layer cannot act as available sites for the rapid accumulation of water, and subsequent oxide hydration, during 'wet' fatigue testing. In fact, the 'micro-composite' interphase of polymer and oxide would be intrinsically crack-resistant and be expected to reduce the local stress concentrations, compared to those present at a planar interface between the low-modulus polymericadhesive and high-modulus oxide-layer. Indeed, an interphase with a graded stiffness, with respect to the various layers, has now been created. Thus, it would appear that basically the benefits which result from the formation of a 'micro-composite' interphase are responsible for the good durability for the CAE-pretreated joints. 


\subsection{PAA-pretreated Joints}

The results for the PAA-pretreated joints shown in Tables 1 and 3 are very intriguing, since the TDCB joints suffer severe attack when tested in the 'wet' environment, but the single-lap joint specimens do not.

Considering firstly the PAA-pretreated TDCB joints, although these joints failed visually along the adhesive/oxide interface, detailed surface analysis via XPS studies revealed that fatigue crack growth in the 'wet' environment actually occurred within the oxide layer itself. Further, the surface analysis studies revealed why the locus of failure was in the oxide layer for the PAA-treated TDCB joints when subjected to 'wet' cyclic-fatigue loading, and why this is accompanied by a correspondingly low value of $G_{t h}$. Firstly, a consideration of the interface thermodynamics revealed why the PAA-pretreated/adhesive interface should not be susceptible to water attack, as was the case for the GBD-pretreated joints. Since, it has been reported that the thermodynamics for water to displace an adhesive from a phosphated-oxide layer are far less favourable than for a GBD-pretreated oxide. Secondly, considering the nature of the oxide layer in detail, there were found to be unfilled pores in the oxide layer of the PAA-pretreated joints, which made this layer intrinsically weak. Thirdly, and most importantly, such unfilled pores would allow the relatively rapid ingress of water into the interphase and permit a relatively high concentration of water molecules to develop in the pores of the oxide layer. Thus, in the PAA-pretreated TDCB joints both (a) the kinetics of water penetration and (b) the presence of sites where relatively high concentrations of water molecules may accumulate are favourable to environmental attack on the oxide layer being initiated by the ingressing water. Finally, from transmission electron microscopy studies, hydrated oxide regions, about $20 \mathrm{~nm}$ in thickness, were observed in-situ in the exposed TDCB joint; and hydrated forms of aluminium oxide are known to be relatively weak. Thus, to summarise, the formation of an hydrated oxide layer in-situ during the 'wet' environmental tests of the PAA-pretreated TDCB joints explains the observed failure path being through this weakened-oxide layer, accompanied by a relatively low value of $G_{t h}$ of 50 $\mathrm{J} / \mathrm{m}^{2}$

Secondly, considering the PAA-pretreated single-lap joints, then when tested in the 'wet' environment the locus of failure remained cohesive through the adhesive layer. The reason why the oxide layer did not fail in the single-lap joint specimens fatigue-tested in the 'wet' environment, as occurred for the corresponding TDCB tests, became clear when electron microscopy studies were undertaken. These revealed that, in the case of these single-lap joint specimens, the porous oxide layer had been penetrated by the adhesive. Hence, the good durability was imparted by the presence of a 'micro-composite' interphase, for the reasons described above in the case of the CAE-pretreated joints. Finally, the crucial differences in the formation, or not, of a 'micro-composite' interphase in 
the single-lap and TDCB joints, respectively, may be ascribed to the preparation methods employed for the two types of specimen. For the latter TDCB joint only a very low pressure could be employed whilst for the former a relatively high and uniform pressure was applied to, and maintained on, the single-lap joint during its preparation. The higher bonding pressure in the case of the single-lap joint is considered to be the important feature which led to the penetration of the adhesive into the porous PAA oxide layer to give a 'micro-composite' interphase, and which thus led to good interphase stability even under cyclic-fatigue loading in a 'wet' environment.

\section{Fatigue Crack Initiation and Propagation in Single-Lap Joints}

\subsection{Introduction}

Much of the previous work undertaken on predicting the lifetime of materials and structures has assumed that most of the lifetime of a bonded joint is dominated by crack propagation, rather than by an initiation phase $[3,4,11]$. However, the initiation and propagation of fatigue cracks in the singlelap joint specimen remains a contentious subject. Hence, a back-face strain technique has been used in the present study to quantify the relative proportion of time spent in the initiation and the subsequent propagation of a crack until failure. This technique has been successfully used by several workers to detect crack initiation $[4,9,12-15]$. However, it is useful to first review some of the literature on the initiation and propagation of cracks in single-lap joints.

\subsection{The Initiation versus Propagation Debate}

Recent debate has focused on whether the fatigue life of a single-lap joint is dominated by the initiation of cracks or by their propagation. However, definitive evidence for which of these aspects is dominant is difficult to locate. In part, this is due to how initiation has been defined and measured, and to the range of different techniques that have been used to detect crack growth. At the simplest level, visual techniques, e.g. video microscopy, tend to indicate that initiation dominates, whilst compliance-based methods, e.g. via back-face strain or specimen compliance measurements, favour a propagation-dominated lifetime. (Also, whether the fatigue life of a single-lap joint is dominated by the initiation of cracks or by their propagation would also be expected to depend upon the details of the geometry of the single-lap joints and/or the fracture properties of the adhesive employed.)

Harris and Fay [16] used video microscopy to observe the side of a single-lap joint, and to identify the initiation of a crack. This study of the fatigue life of adhesives for automotive applications found that the majority of the fatigue life was spent in the initiation of a crack. However, the crack growth was monitored from one side of the joint only, though this technique is really only valid if measurements are taken from both sides of the joint. In addition, cracks in adhesive joints are notoriously difficult to observe, especially when they are small, leading to errors in the estimation of 
the time spent in crack initiation. This approach used also assumed that cracks will only initiate at the edge of the joint towards the end of the overlap. The advantage of the compliance-based methods such as the back-face strain technique is that wherever cracks initiate, be it (a) within the joint at the end of the overlap, or (b) at the edges, the presence of a crack will be detected.

The 'back-face' strain technique was originally developed by Abe et al. [12] to monitor crack initiation and propagation in welded structures. This technique was later applied to adhesive joints by Zhang et al. [13], Imanaka et al. [14], Taylor [9], Curley et al. [4] and Crocombe et al. [15]. Crack initiation is recorded from changes in the strain measured by strain gauges placed on the 'back-face' of the substrate. This technique will be described in more detail below, but it would seem that this insitu technique is a reliable method for assessing when crack initiation has taken place within the joint. Several authors who have applied this technique have found that the lifetime of the adhesive joints is dominated by crack propagation [4,9]. This finding is supported by Krenk et al. [17], who used a specimen compliance method and found that there was no appreciable initiation period, and that a near-constant crack growth rate occurred throughout the joint. Zhang et al. [13] showed, using a backface strain method, that the initiation time can vary with the joint lifetime, i.e. the ratio of initiation to propagation time is not constant. Some authors $[14,15]$ have found a significant initiation period using this technique. However, examining carefully the raw data in these papers shows that in some cases the quoted initiation period would appear to be too large. For example, authors may state that damage evolution has occurred, but maintain that a crack has not initiated [15]. However, comparing the experimental data with the finite element predictions, shows that the observed strain is continuously increasing and is thus associated with crack growth. Hence, in these cases, the joint life may actually be dominated by crack propagation, rather than by initiation as stated by the authors; and indeed when the spew fillets are removed, the initiation period does very clearly become zero [15].

Fernando and Kinloch [18] observed the propagation of cracks using an ultrasonic 'C' scan method to show that the joint lifetime was dominated by crack propagation. In addition, images obtained from the ultrasonic scans also clearly showed that a crack front propagated from each end of the joint. Aglan and Abdo [19] measured the crack growth rate from $2 \mathrm{~mm}$ initial pre-cracks in lap joints, and found that a variable rate of fatigue crack growth occurred, with slow crack growth up to 50000 cycles, followed by a faster propagation rate to up to final failure. They used an optical method of crack measurement along the sides of the joint, which they managed to correlate with ultrasonic and thermal wave measurements at different intervals of the fatigue lifetime. Their results gave no information or comparison with joints which did not contain a pre-existing crack, and so care has to be taken when interpreting their results, and in deciding whether their initial crack was a 'sharp' crack 
or not. This is important as, if a crack is relatively blunt, initiation will occur over longer time-scales due to excessive crack-tip plasticity occurring.

For the same adhesive/substrate system, discrepancies have been found between different methods of detecting crack initiation. For example, Curley et al. [4, 9] and Crocombe [20] studied the same steel-substrate/epoxy-adhesive system. Values measured for the initiation phase from these two studies were found to be less than $15 \%$ and about $60 \%$ respectively. However, Curley et al. used the 'back-face' strain technique, whereas Crocombe used video microscopy. Notwithstanding, closer examination of the experimental data shows important differences in the detailed joint design which may account for these seemingly contrary results. For these tests Curley et al. used a natural spew fillet and substrates of the same dimensions. On the other hand, Crocombe controlled the adhesive fillet and used substrates of different dimensions, to force cracks to propagate from one end of the overlap only. In addition, Crocombe observed that the proportion of the lifetime spent in crack propagation increases as the thickness of the adhesive increases.

In summary, most data show that the fatigue life of single-lap joints is dominated by crack propagation, or at the very least that crack propagation makes up a very significant proportion of the joint lifetime. Indeed, in some cases, the initiation period is observed to be zero. Thus, a clear option in calculating the lifetime of joints under fatigue loading is to assume that the lifetime is controlled by crack propagation, since the design calculations will always then be conservative.

\subsection{The Back-Face Strain Tests}

\subsubsection{Introduction}

For the single-lap joints, the intersections of the interface with the traction-free substrates, i.e. the interface corners, are potential fracture initiation sites because of the stress singularity at the corners. Hence crack initiation, and subsequent propagation, may be recorded from changes in the strain, measured from strain gauges placed on the 'back-face' of the substrate close to the edge of the overlap, see Figure 7. This technique was used to examine whether the crack initiation or the crack propagation dominated the fatigue lifetime of the single-lap joints studied in the present work.

\subsubsection{Finite-Element Analysis (FEA) Studies on Back-Face Strain}

Finite-element analysis (FEA) studies have been performed to investigate how the back-face strain varies when the joints are loaded and as a crack grows through the bonded region. Four possible scenarios were investigated (see Figure 7):

(i) No crack growth; 
(ii) A crack growing only from the G1 side;

(iii) A crack growing only from the G2 side;

(iv) Cracks growing from both the G1 and G2 sides.

The longitudinal strain (in the direction of the strain gauge) at different crack lengths has been obtained from non-linear, large-deformation FEA of the single-lap joint. The strains were calculated at three different positions at $-2,0$ and $+2 \mathrm{~mm}$ on both substrates, as defined in Figure 7 . Here the reference position (i.e. $0 \mathrm{~mm}$ ) is the end of the overlap, and the positive direction is towards the centre of the overlap, whilst the negative direction is along the substrate towards the grips.

The FEA results show that when the single-lap joint is initially loaded, with no crack growth, a constant compressive strain is calculated. The value of this strain depends upon the exact positioning of the strain gauges, but remains constant until crack growth is observed. Figure 8 shows the FEA results for when crack growth does occur, for two different cases. In Figure 8a a single crack is assumed to grow along the interface from the G1 side only. (Note that due to the rotational symmetry of the single-lap joint, for the case when the crack grows only from the G2 side, the corresponding G1 and G2 curves in Figure 8a must be interchanged.) In Figure 8b cracks of equal length are assumed to grow along the interface from both the G1 and G2 sides.

The FEA results show that when a crack starts to grow there is a measurable change in the strain. When the crack grows from one end only, the strain may increase or decrease depending on the position of the strain gauges. However, the signal variation of the strain gauge at the crack side and at the $+2 \mathrm{~mm}$ position is the highest, whilst the change in the opposite strain gauge is moderate. Hence this $+2 \mathrm{~mm}$ position is the preferable position to locate the strain gauge. The same pattern is observed when the cracks are assumed grow from both ends. However, due to symmetry, in this case the strains measured by both gauges are equal if the crack lengths are equal. By comparing the experimental results with the FEA predictions it is possible to determine whether a crack grows from one end, or both ends of the lap joint.

\subsubsection{Results and Discussion}

The single-lap joint specimens were instrumented prior to the above FEA studies being completed and the strain gauges were located approximately in the $0 \mathrm{~mm}$ positions, as shown in Figure 7. The lap joints were then tested in cyclic fatigue as described above. Examples of the results from the backface strain experiments are shown in Figures 9 and 10. As discussed above, when a crack initiates at one end of the single-lap joint specimen there is a change in the compressive strain measured from the 
gauge on the 'back-face' of the joint where the crack is located, and the opposite gauge measures a simultaneous change in the compressive strain, see Figure 8.

The data shown in Figure 9 are from a CAE-pretreated single-lap joint specimen, which was fatigued at a maximum stress corresponding to $40 \%$ of its static failure strength. Over most of the fatigue life, the strain measured by both gauges is constant. Note that the initial change in the measured strain is thought to be due to the cyclic softening of the adhesive [16,17], and is frequently observed using this technique, [e.g. 4,9,15]. The constant strain which is recorded indicates that no crack has been detected. Indeed, no crack growth was expected, since the maximum load applied during the test was $40 \%$ of the monotonic failure load, $T_{f}$, and this value is actually at the observed threshold of $40 \%$ of $T_{f}$, as shown in Table 3. At and below the threshold, the joint lifetime becomes effectively infinite, and indeed this test was stopped without joint failure being recorded. (Note that the difference between the readings from gauges G1 and G2 is considered to be due to a slight difference in the positioning of the gauges, see Figure 8, and to the different sizes of the natural spew fillets at either end of the joint.)

In contrast, at cyclic-fatigue maximum loads above the threshold value, the initiation and propagation of fatigue-induced cracks were observed. Crack initiation may be identified to have occurred when the strain measured by both gauges ceases to be constant, as discussed above and as shown in Figure 8. The data in Figure 10 show none of the features seen in Figure 9, as there is no significant proportion of the lifetime where the measured strains are constant. Hence, it is evident that crack initiation occurs soon after the start of the fatigue test. Although it is difficult to put an exact value on the number of cycles to initiation, due to the noise in the experimental data, it is clear that crack initiation has occurred within 50,000 cycles. Comparing the experimental data shown in Figure 10 with the FEA predictions shown in Figure 8, two cracks appear to be growing during this fatigue test, with gauge G1 having been positioned at approximately $0 \mathrm{~mm}$ and gauge $\mathrm{G} 2$ towards the $-2 \mathrm{~mm}$ position, see Figure 7 . Hence, about $95 \%$ of the fatigue life of this single-lap joint specimen is occupied by the propagation of cracks, as opposed by their initiation. Such observations are in good agreement with those from earlier work by Curley et al. [4] who used the back-face strain technique to estimate the proportion of fatigue life spent in initiation and propagation for steel single-lap joints. They tested steel lap-joints in water at $28^{\circ} \mathrm{C}$ and found that the time required for the initiation of a fatigue crack was always less than $25 \%$ of the joint lifetime, and in most cases less than $1 \%$.

In summary, the fatigue life of the single-lap joint specimens is predominantly occupied by the propagation of cracks, as opposed to their initiation. Hence, it should be possible to use analytical and numerical models, coupled with the experimental fracture-mechanics results, to evaluate the 
fatigue performance of the single-lap joint based on this assumption, assuming of course that the relatively short-term fracture mechanics tests accurately reflect the mechanisms of attack that will be seen in the in-service components over a longer timescale. These aspects will be discussed in Part II of the present work [5].

\section{Conclusions}

Monotonically-loaded tests undertaken in a 'dry' environment using the TDCB specimens gave measured values for the adhesive fracture energy, $G_{c}$, of $1600 \pm 150 \mathrm{~J} / \mathrm{m}^{2}$ for the CAE- and PAApretreated joints, and all these joints failed via cohesive failure through the adhesive. However, for the GBD-pretreated specimens a $G_{c}$ value of only $600 \pm 100 \mathrm{~J} / \mathrm{m}^{2}$ was measured, and the locus of failure was found to be a mixture of interfacial and cohesive fracture, which explains the lower value of $G_{c}$ for these joints. In the case of the single-lap joint tests, for the CAE- and PAA-pretreated specimens the locus of joint failure was visually assessed to be via cohesive failure through the adhesive, whilst for the GBD-pretreated specimens the locus of failure was a mixture of interfacial/cohesive fracture. For these monotonically-loaded tests, these observations on the locus of failure for the single-lap joint specimens were identical to those recorded for the corresponding TDCB specimens tested under monotonic-loading conditions.

It has been possible to measure a fatigue threshold, $G_{t h}$, for the TDCB specimens tested under cyclic-fatigue loading. In such tests, the effect of the surface treatment was very pronounced when tests were undertaken in the 'wet' environment. Here, the threshold strain-energy release-rate, $G_{t h}$, was significantly higher for the CAE-pretreated than for the GBD- and PAA-pretreated joints. Also the failure mechanism was found to correlate with the measured values of $G_{t h}$. The failure mechanisms have been discussed and the fracture-mechanics data were successfully modelled using a modified Paris law relationship, enabling them to be used for predicting the lifetime of bonded joints and structures, as will be discussed in Part II [5]. The single-lap joints were also tested under cyclicfatigue loading in the 'wet' environment. The observations from the fatigue behaviour, in terms of the mechanical performance and locus of joint failure, of the single-lap joint tests in the 'wet' environment were similar to the corresponding TDCB tests in the case of the GBD- and the CAEpretreated joints. There were, however, clear discrepancies in the case of the PAA-pretreated joints, and these could be readily explained by reference to the known failure mechanisms and the different methods of preparation used for the TDCB and single-lap joint specimens.

Finally, a back-face strain technique was used to investigate the relative proportions of the lifetime of single-lap joints occupied by the processes of crack initiation and crack propagation. These data showed that the fatigue lifetime of the lap joints is dominated by the propagation of fatigue 
cracks, which accounted almost the entire measured lifetime. Thus, in Part II of the present studies [5], experimental results from the fracture-mechanics tests will be combined with analytical and numerical models to predict the cyclic-fatigue performance of single-lap joints based upon the concept that the fatigue lifetime of these joints is controlled by crack propagation through the joint. 


\section{Acknowledgements}

The authors wish to thank the EPSRC for financial support through a Platform Grant (HH) and the Royal Academy of Engineering for a Post-Doctoral Research Fellowship for Dr. A.C. Taylor. We would also like to thank Professor S.J. Shaw and Dr. I. Ashcroft of Qinetiq (Farnborough) for helpful discussions. 


\section{References}

[1] Kinloch AJ. Adhesion and Adhesives: Science and Technology, Chapman and Hall, London, 1987.

[2] Kinloch AJ, Little MSG and Watts JF. Acta Materialia 2000; 48:4543.

[3] Curley AJ, Jethwa JK, Kinloch AJ and Taylor AC. J. Adhesion 1998; 66:39.

[4] Curley AJ, Hadavinia H, Kinloch AJ and Taylor AC. Int. J.Fracture 2000;103:41.

[5] Hadavinia H, Kinloch AJ, Little MSG and Taylor AC. Submitted to Int. J. Adhesion Adhesives, 2003.

[6] Little MSG. The durability of structural adhesive joints. PhD, Univ. of London, 1999.

[7] Adhesion, Adhesives and Composites Group Website, Imperial College London, http://www.me.imperial.ac.uk/AACgroup/index.html.

[8] Blackman BRK, Hadavinia H, Kinloch AJ, Paraschi $M$ and Williams JG. Eng. Fracture Mechanics 2003;70:233.

[9] Taylor AC. The impact and durability performance of adhesively bonded metal joints. PhD, Univ. of London, 1997.

[10] Martin RH and Murri GB. 1990; ASTM STP 1059:251.

[11] Kinloch AJ and Osiyemi SO. J. Adhesion 1993; $43: 79$.

[12] Abe, H. and Satoh, T. J. Welding Soc. Japan, 1992;10:272.

[13] Zhang Z, Shang JK and Lawrence FV. J. Adhesion 1995; 49:23.

[14] Imanaka M, Haraga K and Nishikawa T. J. Adhesion 1995; 49:197.

[15] Crocombe AD, Ong CY, Chan CM, Abdel Wahab MM and Ashcroft IA. J. Adhesion 2002; 78:745.

[16] Harris JA and Fay PA. Int. J. Adhesion Adhesives 1992;12:9.

[17] Krenk S, Jonsson J and Hansen LP. Eng. Fracture Mechanics 1996; 53:859.

[18] Fernando M and Kinloch AJ. Unpublished work.

[19] Aglan H and Abdo Z. J. Adhesion Sci. Technol. 1996;10:183.

[20] Crocombe AD. In Proceedings of 'Structural Adhesives in Engineering V (SAE V)', Bristol. Institute of Materials, 1998; 80. 


\section{Tables}

Table 1: Experimental results from the TDCB specimens.

\begin{tabular}{|c|c|c|c|c|}
\hline & & $\begin{array}{c}\text { Gritblast and } \\
\text { Degrease (GBD) }\end{array}$ & $\begin{array}{l}\text { Chromic Acid Etch } \\
\text { (CAE) }\end{array}$ & $\begin{array}{c}\text { Phosphoric Acid Anodise } \\
\text { (PAA) }\end{array}$ \\
\hline \multirow{2}{*}{$\begin{array}{l}\text { Monotonic } \\
\text { tests }\end{array}$} & $G_{c} \pm \mathrm{SD}\left(\mathrm{J} / \mathrm{m}^{2}\right)$ & $600 \pm 100$ & $1550 \pm 50$ & $1650 \pm 100$ \\
\hline & LoF & $\bar{M}$ & $\bar{C}$ & $\bar{C}$ \\
\hline \multirow{3}{*}{$\begin{array}{l}\text { 'Dry' } \\
\text { fatigue tests }\end{array}$} & $G_{t h}\left(\mathrm{~J} / \mathrm{m}^{2}\right)$ & 125 & 200 & 200 \\
\hline & $G_{t h} / G_{c}$ & 0.21 & 0.13 & 0.12 \\
\hline & LoF & $\mathrm{M}$ & $\mathrm{C}$ & $\mathrm{C}$ \\
\hline \multirow{3}{*}{$\begin{array}{l}\text { 'Wet' } \\
\text { fatigue tests }\end{array}$} & $G_{t h}\left(\mathrm{~J} / \mathrm{m}^{2}\right)$ & 25 & 200 & 50 \\
\hline & $G_{t h} / G_{c}$ & 0.04 & 0.13 & 0.03 \\
\hline & LoF & $\mathrm{I}$ & $\mathrm{C}$ & $\mathrm{I}$ \\
\hline
\end{tabular}

Note: Visually assessed locus of joint failure (LoF): C: cohesive through the adhesive; M: mixed cohesive through the adhesive and along the adhesive/substrate interface; I: interfacial along the adhesive/substrate interface. 
Table 2: Fatigue coefficients from Equation (1) extracted from the experimental fracture-mechanics data from tests conducted using the TDCB specimens.

\begin{tabular}{|c|c|c|c|c|c|}
\hline & \multicolumn{2}{|c|}{$\begin{array}{c}\text { Gritblast and Degrease } \\
\text { (GBD) }\end{array}$} & $\begin{array}{c}\text { Chromic-Acid Etch } \\
\text { (CAE) }\end{array}$ & \multicolumn{2}{|c|}{$\begin{array}{c}\text { Phosphoric-Acid Anodise } \\
\text { (PAA) }\end{array}$} \\
\hline Coefficient & Dry & Wet & Dry and Wet & Wry \\
\hline $\begin{array}{c}\text { D } \\
\left(\mathrm{m}^{2} / \mathrm{N} . c y c l e\right)\end{array}$ & $1.61 \times 10^{-23}$ & $8.49 \times 10^{-13}$ & $1.51 \times 10^{-26}$ & $1.59 \times 10^{-21}$ & $1.41 \times 10^{-13}$ \\
\hline$n$ & 6.35 & 2.89 & 7.52 & 5.55 & 2.85 \\
\hline$n_{1}$ & 10 & 10 & 10 & 10 & 10 \\
\hline$n_{2}$ & 10 & 10 & 10 & 1650 & 1650 \\
\hline$G_{c}\left(\mathrm{~J} / \mathrm{m}^{2}\right)$ & 600 & 600 & 1550 & 0.73 & 0.73 \\
\hline$G_{t h}\left(\mathrm{~J} / \mathrm{m}^{2}\right)$ & 125 & 25 & 200 & 200 & 50 \\
\hline$a_{0}(\mathrm{~mm})$ & 1.10 & 1.10 & 0.78 & 10 & 10 \\
\hline
\end{tabular}

Note: Values of $a_{o}$ from Equation (2). 
Table 3: Experimental results from the single-lap joint test specimens.

\begin{tabular}{|c|c|c|c|c|}
\hline & & $\begin{array}{c}\text { Gritblast and } \\
\text { Degrease (GBD) }\end{array}$ & $\begin{array}{c}\text { Chromic-Acid Etch } \\
\text { (CAE) }\end{array}$ & $\begin{array}{c}\text { Phosphoric-Acid } \\
\text { Anodise (PAA) }\end{array}$ \\
\hline \multirow{3}{*}{$\begin{array}{c}\text { Monotonic } \\
\text { tests }\end{array}$} & $T_{f} \pm \mathrm{SD}(\mathrm{kN} / \mathrm{m})$ & $274 \pm 24$ & $538 \pm 17$ & $569 \pm 18$ \\
\cline { 2 - 5 } & $\sigma_{f} \pm \mathrm{SD}(\mathrm{MPa})$ & $21.6 \pm 1.9$ & $42.2 \pm 1.3$ & $44.8 \pm 1.4$ \\
\cline { 2 - 5 } & $\mathrm{LoF}$ & $\mathrm{M}$ & $\mathrm{C}$ & $\mathrm{C}$ \\
\hline \multirow{3}{*}{$\begin{array}{c}\text { 'Dry' } \\
\text { fatigue tests }\end{array}$} & $T_{t h}(\mathrm{kN} / \mathrm{m})$ & 85 & 215 & 225 \\
\cline { 2 - 5 } & $T_{t h} / T_{f}$ & 0.31 & 0.40 & 0.40 \\
\cline { 2 - 5 } & $\mathrm{LoF}$ & $\mathrm{M}$ & $\mathrm{C}$ & $\mathrm{C}$ \\
\hline \multirow{3}{*}{\begin{tabular}{c} 
fatigue tests \\
\cline { 2 - 5 }
\end{tabular}} & $T_{t h}(\mathrm{kN} / \mathrm{m})$ & 50 & 215 & 225 \\
\cline { 2 - 6 } & $T_{t h} / T_{f}$ & 0.18 & 0.40 & 0.40 \\
\cline { 2 - 5 } & $\mathrm{LoF}$ & $\mathrm{I}$ & $\mathrm{C}$ & $\mathrm{C}+\mathrm{S}$ \\
\hline
\end{tabular}

Note: Visually assessed locus of joint failure (LoF): C: cohesive through the adhesive; M: mixed/cohesive through the adhesive and along the adhesive/substrate interface; I: interfacial along the adhesive/substrate interface; S: cohesive in the substrate. 


\section{Figures Caption}

Figure 1: Geometry and dimensions of the (a) adhesively-bonded tapered double-cantilever beam (TDCB) joints and (b) single-lap joint (SLJ) specimens. (All dimensions in $\mathrm{mm})$.

Figure 2: $\quad$ Comparison of experimental data and the theoretical prediction (via Equation (1)) for 'dry' and 'wet’ fatigue specimens for the GBD-pretreated TDCB joints.

Figure 3: $\quad$ Comparison of experimental data and the theoretical prediction (via Equation (1)) for 'dry' and 'wet' fatigue specimens for the CAE-pretreated TDCB joints.

Figure 4: $\quad$ Comparison of experimental data and the theoretical prediction (via Equation (1)) for 'dry' and 'wet' fatigue specimens for the PAA-pretreated TDCB joints.

Figure 5: $\quad$ Variation of maximum applied load per unit width, $T_{\max }$, with the logarithmic number of cycles to failure, $N_{f}$, for SLJ specimens prepared using the GBD, CAE and PAA pretreatments and tested in the ‘dry’ environment.

Figure 6: $\quad$ Variation of maximum applied load per unit width, $T_{\max }$, with the logarithmic number of cycles to failure, $N_{f}$, for SLJ specimens prepared using the GBD, CAE and PAA pretreatments and tested in the 'wet' environment.

Figure 7: $\quad$ The 'back-face’ strain technique for a single-lap joint.

Figure 8: $\quad$ Non-linear geometry FEA of 'back-face' strain versus crack length in the single-lap joint at an applied load of $150 \mathrm{kN} / \mathrm{m}$. (a) Crack was assumed to grow only from G1 side (see Figure 7), (b) Crack was assumed to grow from both sides.

Figure 9: $\quad$ Back-face strain versus number of cycles for a CAE-pretreated SLJ specimen. The test was conducted in the 'dry' environment at a maximum stress equivalent to $40 \%$ of the static strength of the SLJ.

Figure 10: $\quad$ Back-face strain versus number of cycles for a GBD-pretreated SLJ specimen. The test was conducted in the 'dry' environment at a maximum stress equivalent to $50 \%$ of the static strength of the SLJ. 


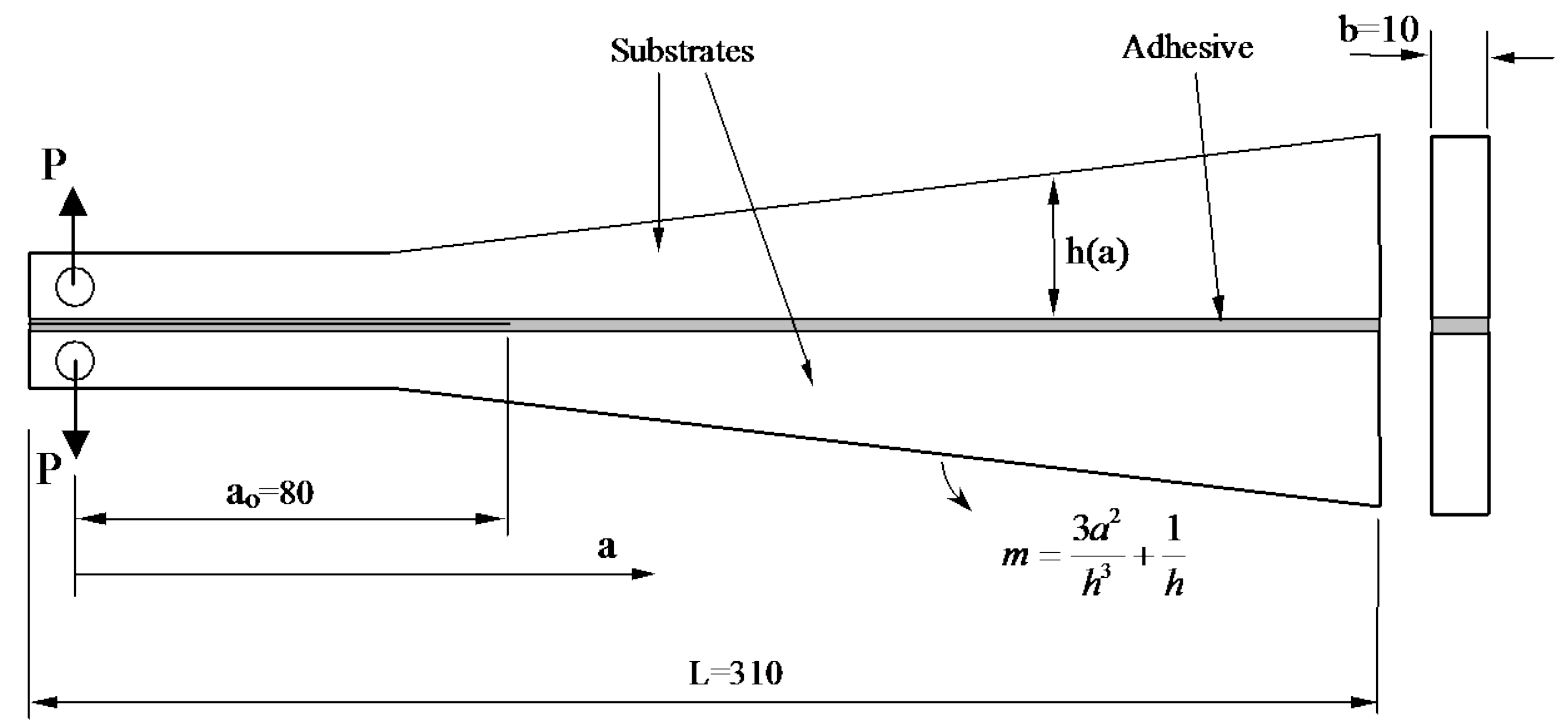

(a)

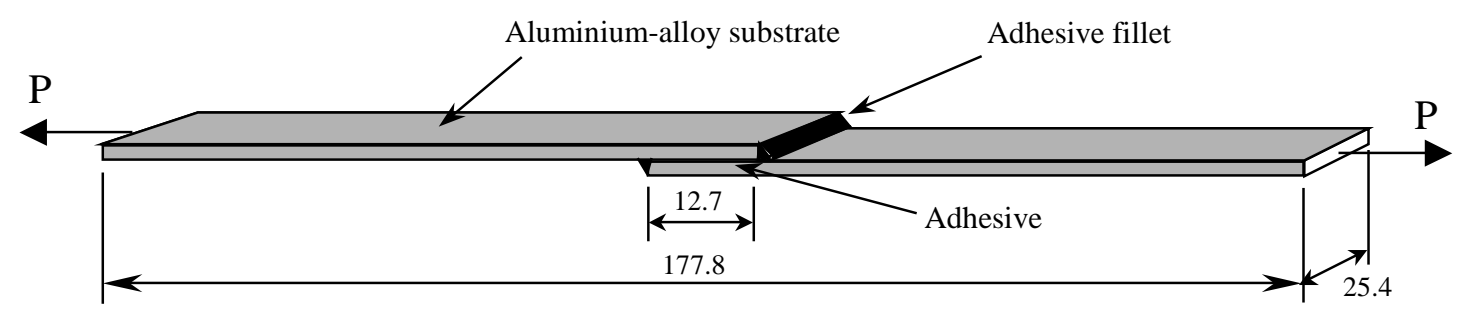

(b)

Figure 1: Geometry and dimensions of the (a) adhesively-bonded tapered double-cantilever beam (TDCB) joints and (b) single-lap joint (SLJ) specimens. (All dimensions in mm). 


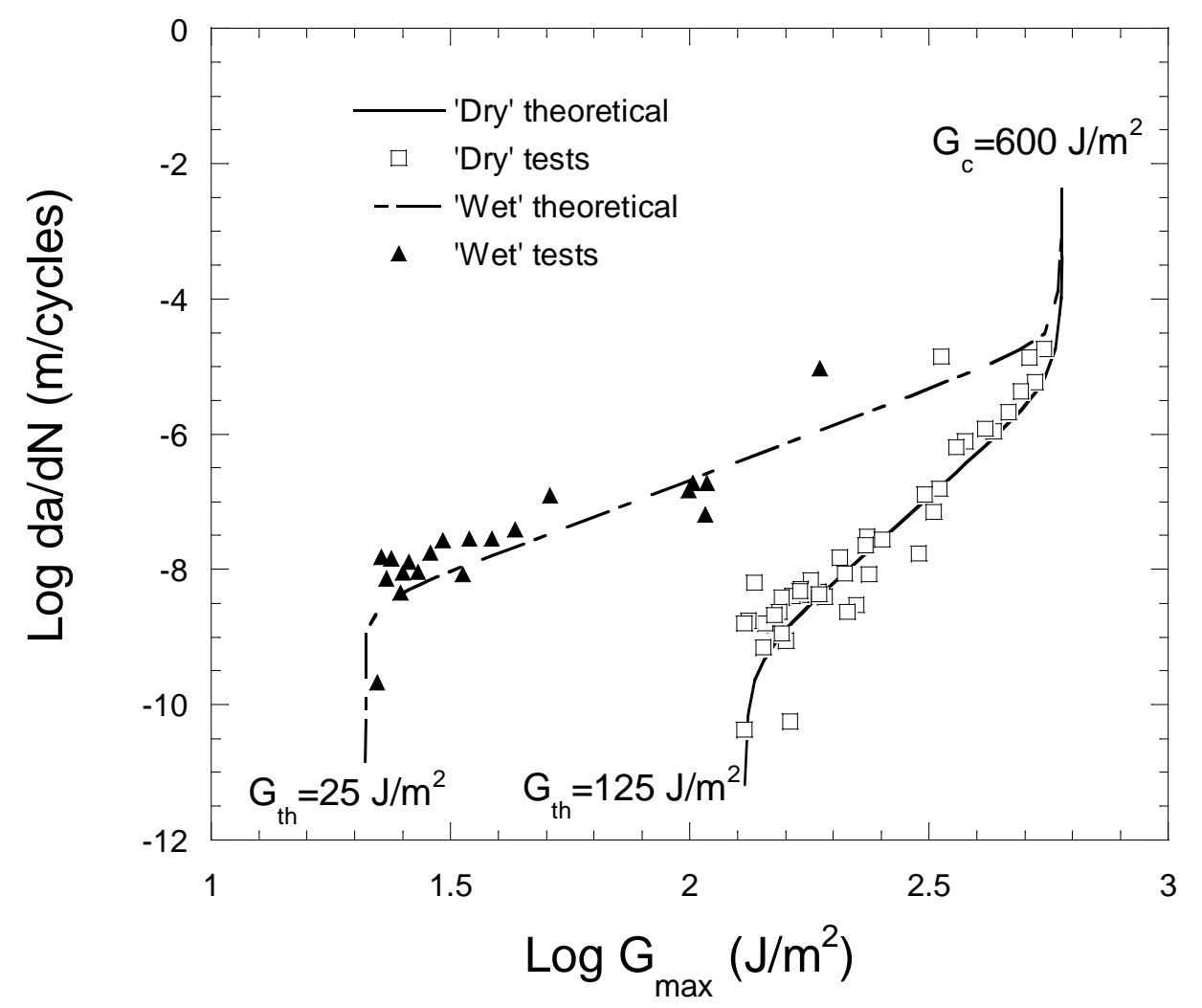

Figure 2: Comparison of experimental data and the theoretical prediction (via Equation (1)) for 'dry' and 'wet' fatigue specimens for the GBD-pretreated TDCB joints. 


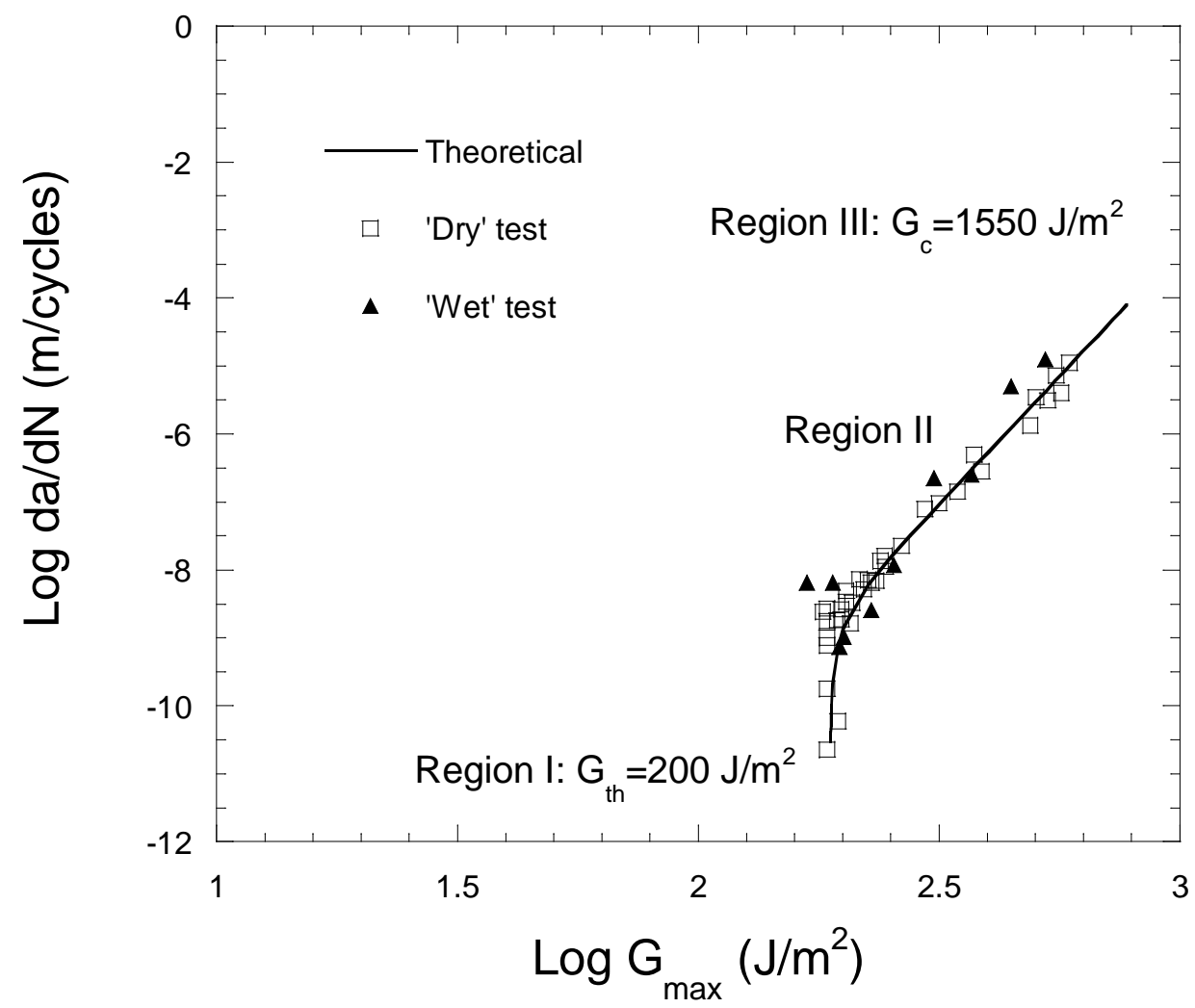

Figure 3: Comparison of experimental data and the theoretical prediction (via Equation (1)) for 'dry' and 'wet' fatigue specimens for the CAE-pretreated TDCB joints. 


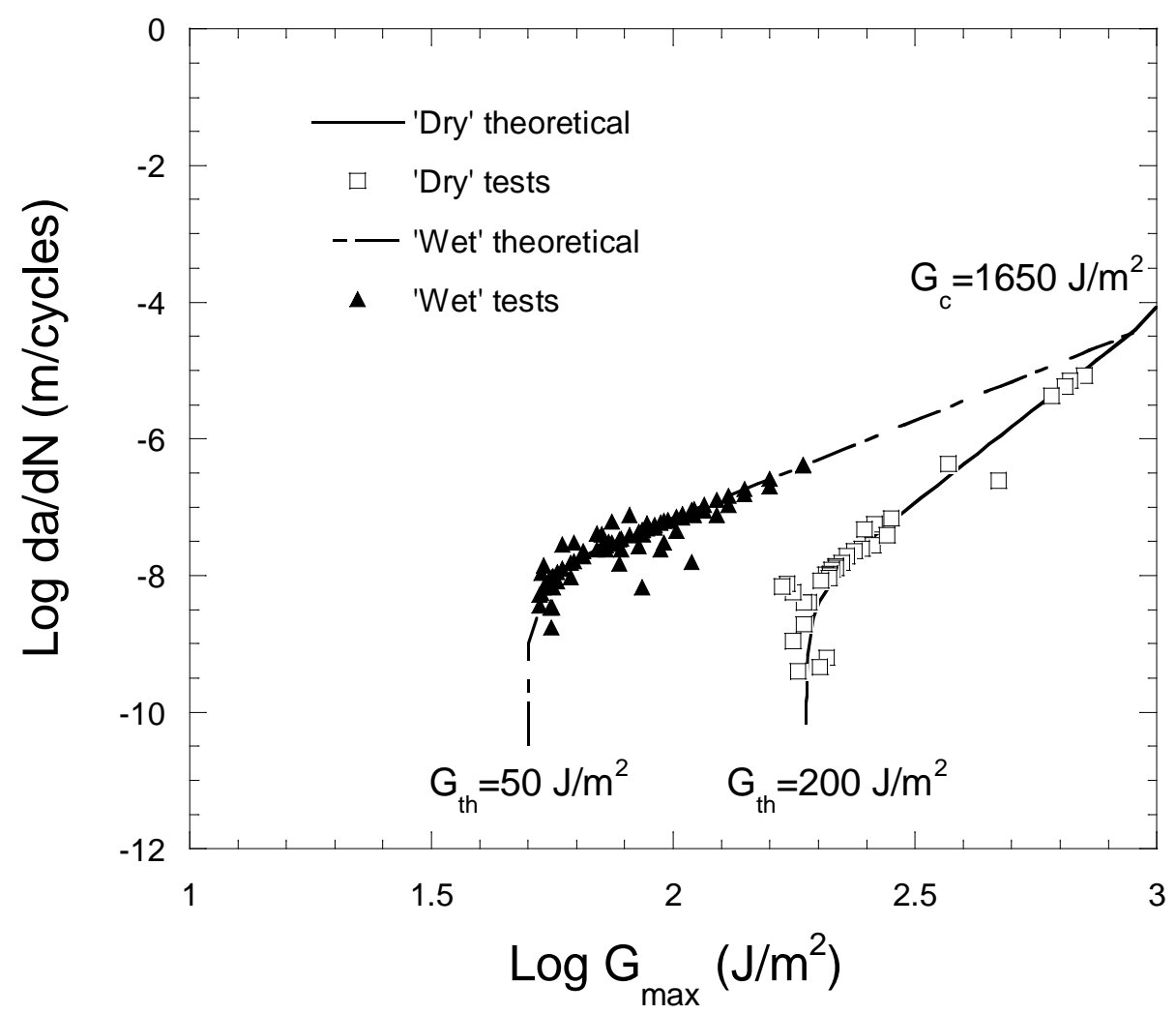

Figure 4: Comparison of experimental data and the theoretical prediction (via Equation (1)) for 'dry' and 'wet' fatigue specimens for the PAA-pretreated TDCB joints. 


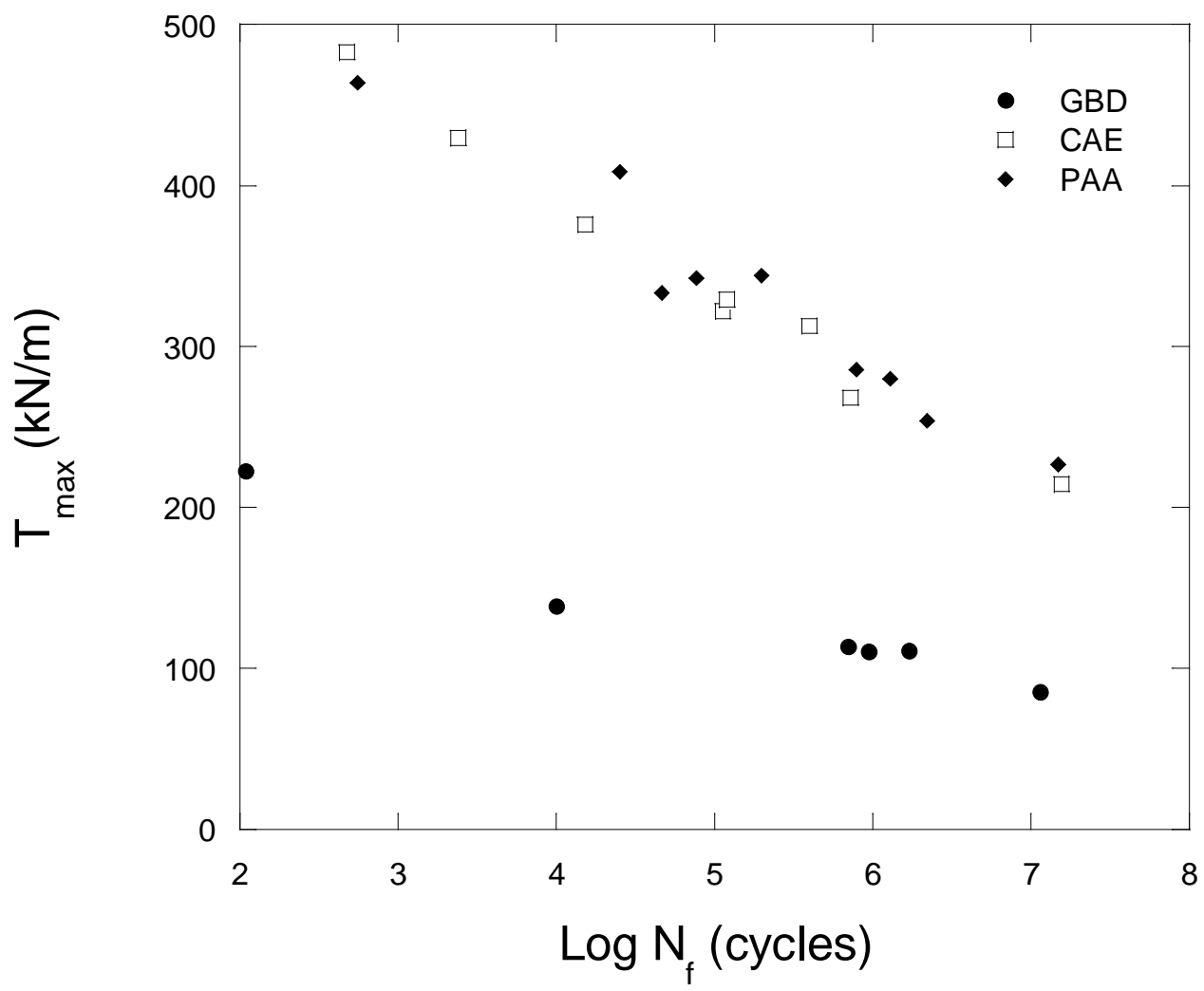

Figure 5: Variation of maximum applied load per unit width, $T_{\max }$, with the logarithmic number of cycles to failure, $N_{f}$, for SLJ specimens prepared using the GBD, CAE and PAA pretreatments and tested in the 'dry' environment. 


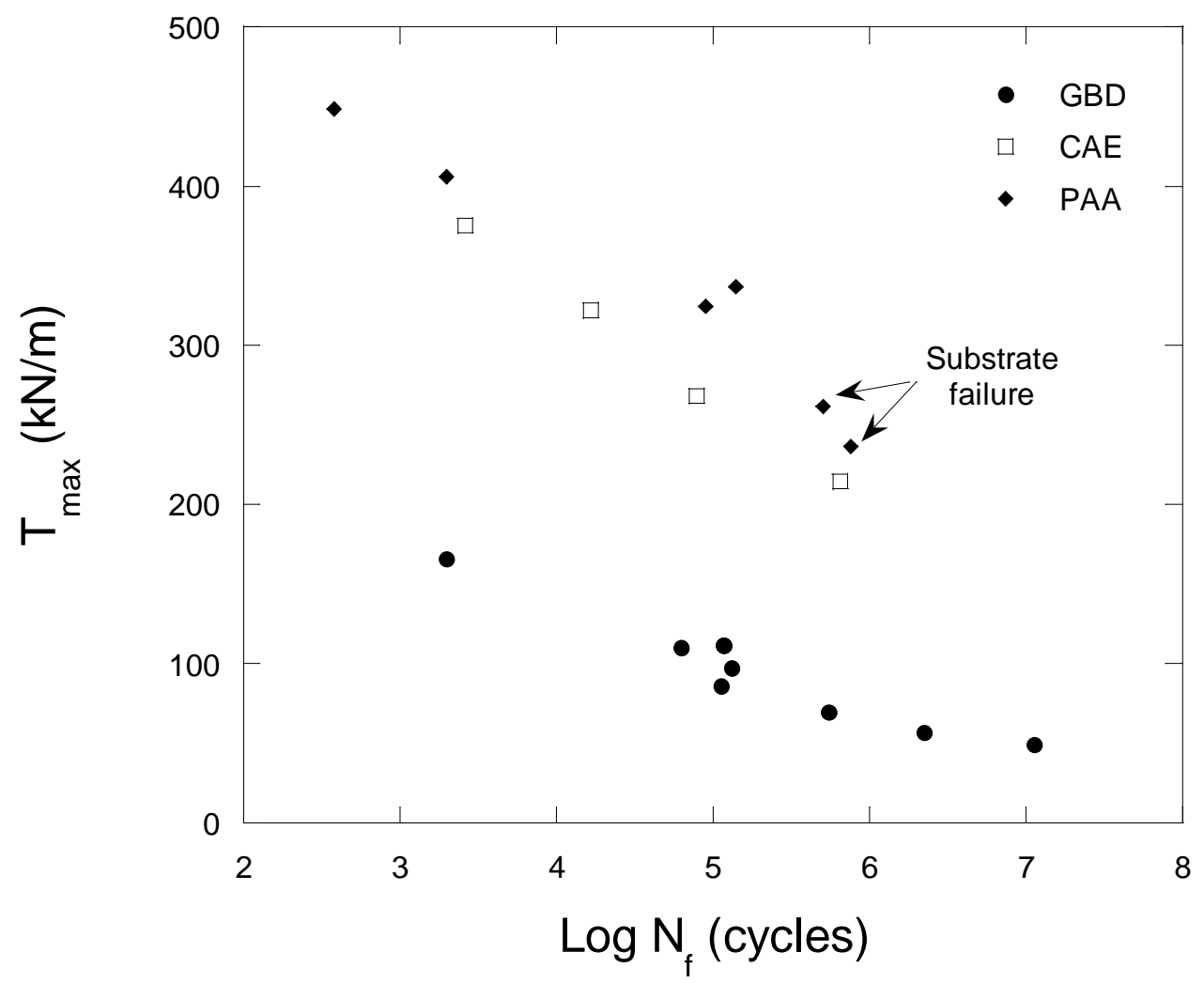

Figure 6: Variation of maximum applied load per unit width, $T_{\max }$, with the logarithmic number of cycles to failure, $N_{f}$, for SLJ specimens prepared using the GBD, CAE and PAA pretreatments and tested in the 'wet' environment. 


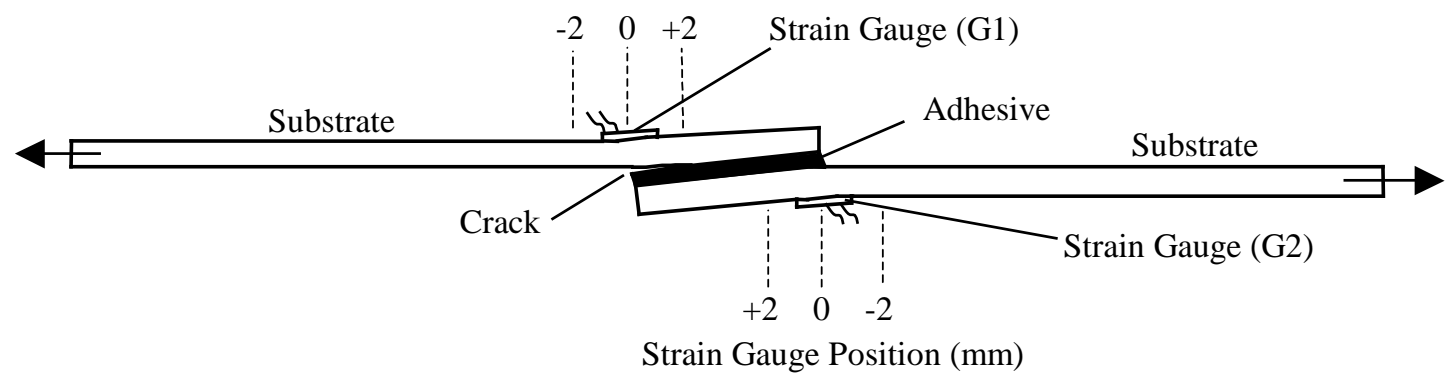

Figure 7: The 'back-face’ strain technique for a single-lap joint. 


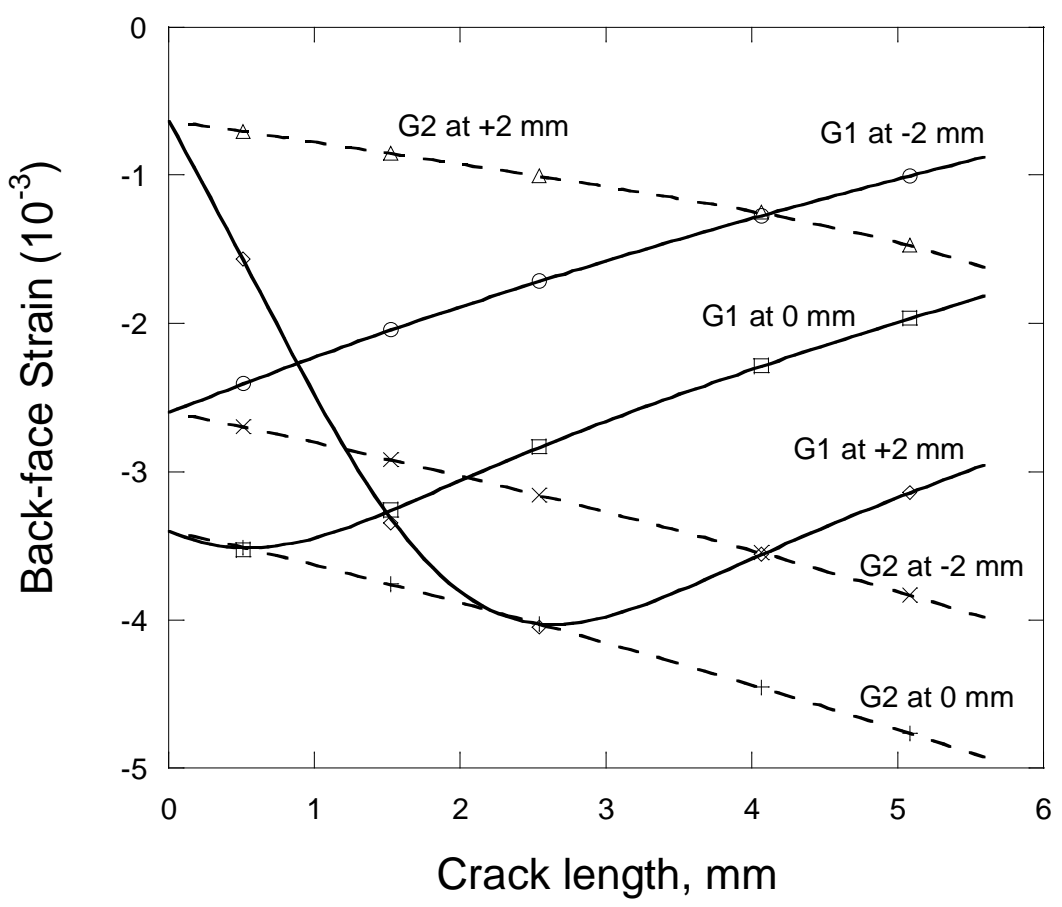

(a)

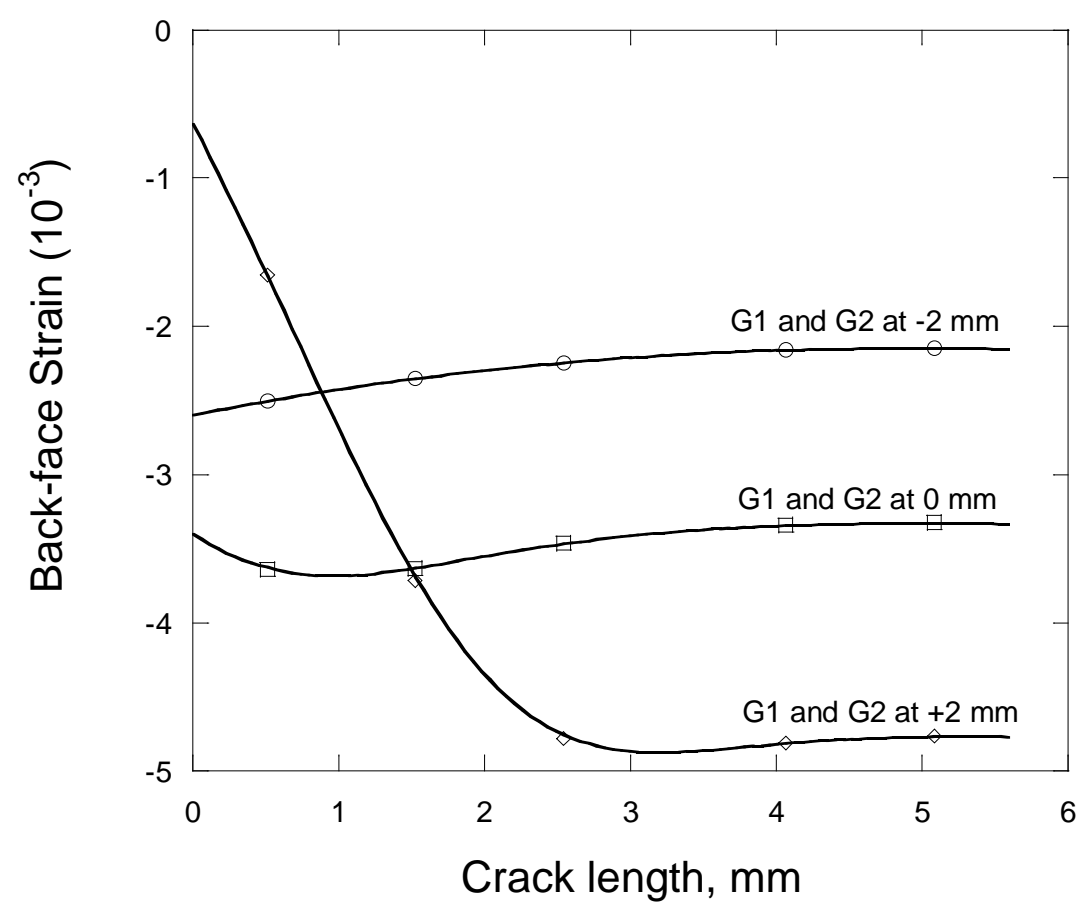

(b)

Figure 8: Non-linear geometry FEA of 'back-face' strain versus crack length in the single-lap joint at an applied load of $150 \mathrm{kN} / \mathrm{m}$. (a) Crack was assumed to grow only from G1 side (see Figure 7), (b) Crack was assumed to grow from both sides. 


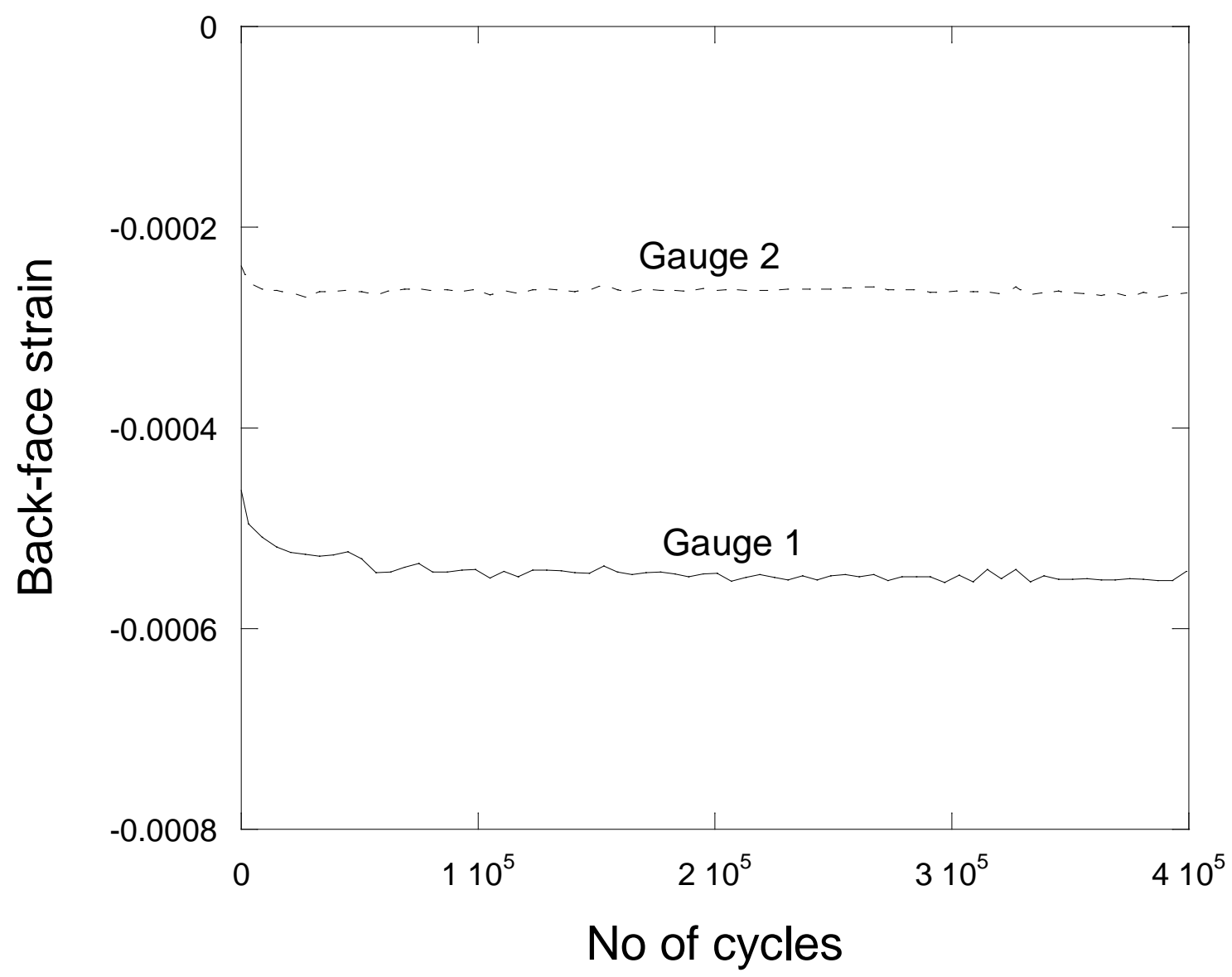

Figure 9: Back-face strain versus number of cycles for a CAE-pretreated SLJ specimen. The test was conducted in the 'dry' environment at a maximum stress equivalent to $40 \%$ of the static strength of the SLJ. 


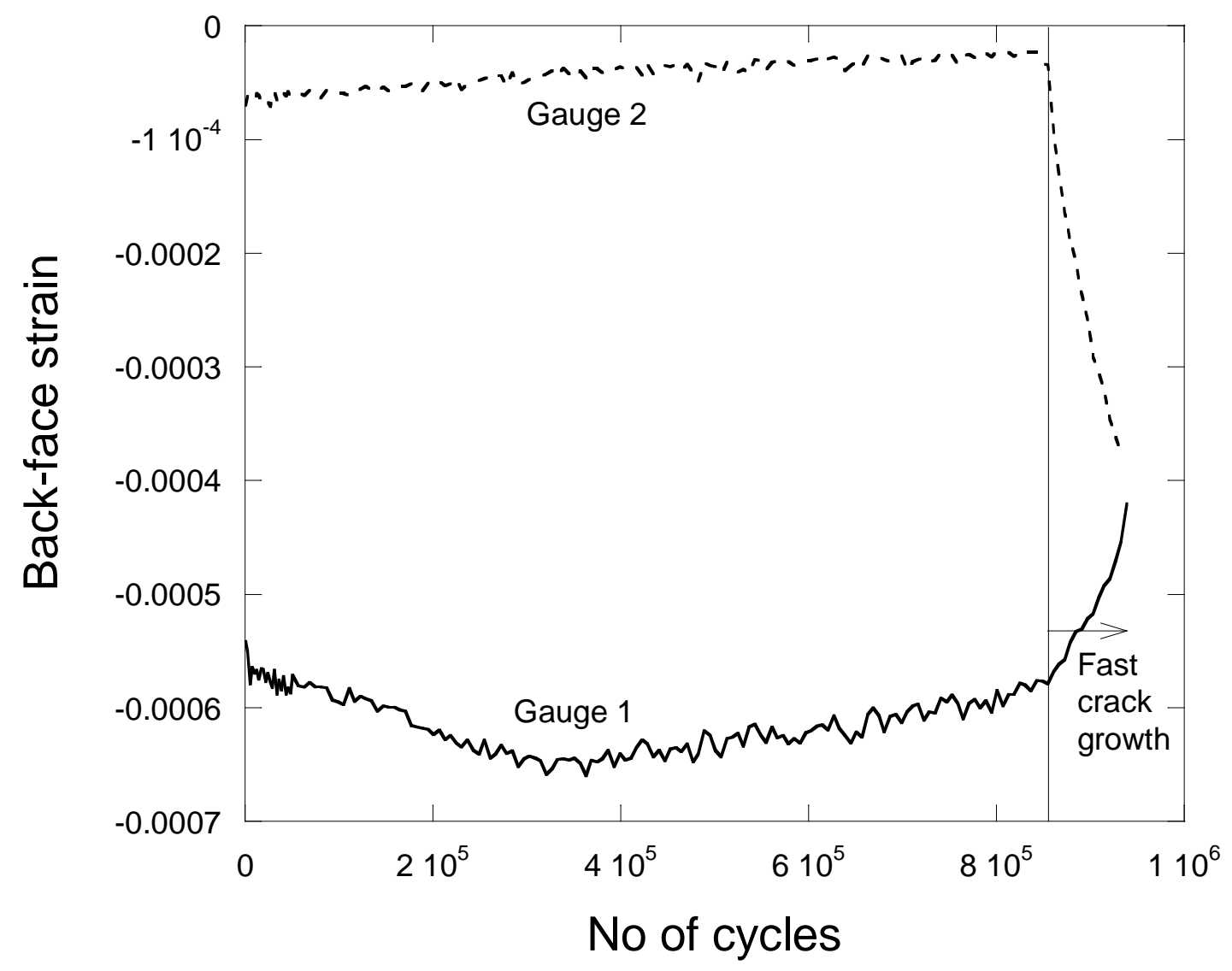

Figure 10: Back-face strain versus number of cycles for a GBD-pretreated SLJ specimen. The test was conducted in the 'dry' environment at a maximum stress equivalent to $50 \%$ of the static strength of the SLJ. 